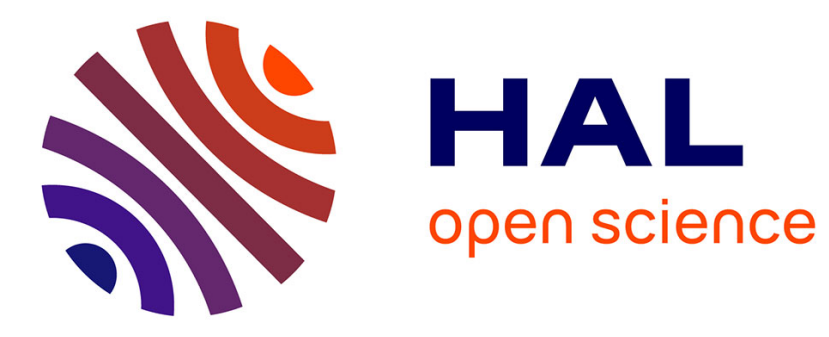

\title{
Influence of the polymer matrix on the viscoelastic behaviour of vitrimers
}

Yann Spiesschaert, Christian Taplan, Lucas Stricker, Marc Guerre, Johan Winne, Filip Du Prez

\section{- To cite this version:}

Yann Spiesschaert, Christian Taplan, Lucas Stricker, Marc Guerre, Johan Winne, et al.. Influence of the polymer matrix on the viscoelastic behaviour of vitrimers. Polymer Chemistry, 2020, 11 (33), pp.5377-5385. 10.1039/D0PY00114G . hal-02614116

\section{HAL Id: hal-02614116 https://hal.science/hal-02614116}

Submitted on 6 Jul 2021

HAL is a multi-disciplinary open access archive for the deposit and dissemination of scientific research documents, whether they are published or not. The documents may come from teaching and research institutions in France or abroad, or from public or private research centers.
L'archive ouverte pluridisciplinaire HAL, est destinée au dépôt et à la diffusion de documents scientifiques de niveau recherche, publiés ou non, émanant des établissements d'enseignement et de recherche français ou étrangers, des laboratoires publics ou privés. 


\title{
Influence of the polymer matrix on the viscoelastic behaviour of vitrimers
}

Received 00th January 20xx, Accepted 00th January 20xx DOI: $10.1039 / x 0 x \times 00000 x$

\author{
Yann Spiesschaert, ${ }^{\ddagger a}$ Christian Taplan, ${ }^{\ddagger a}$ Lucas Stricker, ${ }^{a}$ Marc Guerre, ${ }^{* a, c}$ Johan M. Winne ${ }^{* b}$ and \\ Filip E. Du Prez *a
}

\begin{abstract}
Vitrimer materials are a rapidly growing field of research, in which still many fundamental aspects of material design remain to be explored. In this study, we report a systematic study about the effect of the choice of the matrix on a dynamic covalent bond exchange reaction in a polymer network. In some way, this investigation follows the logic of a 'solvent effect' study that is typical for the development of an organic reaction or synthetic method in solution. Thus, this work constitutes a study of matrix effects on the viscoelastic properties of vitrimers, in particular with regard to their stress-relaxation behaviour. For that purpose, the dynamic transamination within vinylogous urethanes (VU) vitrimers, derived from a wide range of different commercially available diols, was chosen as vitrimer chemistry reaction platform. Additionally, the influence of the molecular weight, and thus the cross-link density, was also investigated using two oligomeric diols of different molecular weights. It was found that changing the molecular weight resulted in vitrimers with significantly different activation energies

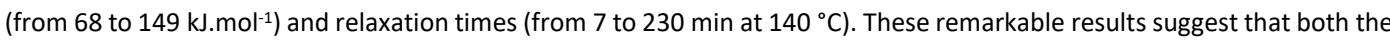
molecular weight and the nature of the polymer matrix have a large influence on the resulting viscoelastic properties. However, no straightforward prediction of relaxation times or activation energies is possible at this stage, and it becomes clear that many more structure-reactivity studies will be required to arrive at a more general understanding of the factors that underly vitrimer properties.
\end{abstract}

\section{Introduction}

Vitrimers are an emerging sub-class of covalent adaptable networks (CANs) constituted of reversible bonds that exchange upon heat without loss of the chemical cross-link density through an associative mechanism, with a thermal response that defies classical distinctions between thermoplastic and thermosetting polymers. ${ }^{1-4}$ The bond exchange chemistry allows the network topology to be rearranged by means of an external directive force in a viscoelastic liquid state, providing an inherent ability to be reprocessed and recycled. This behaviour indeed contrasts with the one of conventional thermosetting materials, which are irreversibly cross-linked. Furthermore, unlike thermoplastics, vitrimers do not show a sudden drop in viscosity upon heating. In contrast, as a result of the underlying associative mechanism, the stress-relaxation in vitrimers exhibits a more gradual temperature response, often

\footnotetext{
a. Polymer Chemistry Research group, Centre of Macromolecular Research (CMaC), Department of Organic and Macromolecular Chemistry, Ghent University, Krijgslaan 281 S4-bis, Ghent B-9000, Belgium

b. Laboratory of Organic Synthesis, Department of Organic and Macromolecular Chemistry, Ghent University, Krijgslaan 281 (S4), 9000 Ghent, Belgium

c. Laboratoire des IMRCP, Université de Toulouse, CNRS UMR5623, Université Paul Sabatier, 118 route de Narbonne, 31062 Toulouse Cedex 9, France

Email:guerre@chimie.ups-tlse.fr, johan.winne@UGent.be,filip.duprez@UGent.be ¥ These authors contributed equally to this work.
}

Electronic Supplementary Information (ESI) available: [details of any supplementary information available should be included here]. See DOI: 10.1039/x0xx00000x adhering to an Arrhenius-like correlation. ${ }^{5-13}$ The linear dependency between viscosity and temperature, and the absence of sudden transitions to low viscosity states, similar to a strong glass forming behaviour of vitreous silica, enables reprocessability over a wide temperature range, without the need for a precise control of the processing temperature. Therefore, vitrimers represent a promising class of polymer networks, particularly, towards the development of crosslinked materials for a circular economy. ${ }^{14,} 15$ However, the research field of vitrimers is relatively young, and the major focus was until now directed towards the development of new chemical platforms. ${ }^{1,7,9,16-25}$ Consequently, many fundamental aspects of vitrimers, as compared to the classical thermoset and thermoplastic polymers, are still not fully understood and require careful investigation. ${ }^{3,4}$ In order to be able to further develop these materials towards industrial applications, a better understanding of the relations between the network dynamics and the underlying network structure and bond exchange reactivity will be critical. ${ }^{3}$

Since the dynamic character of vitrimers, or even CANs in general, can be regarded as perfectly isothermic (and even isergonic) equilibrium reactions between chemically identical but topologically differing moieties, the dynamics of vitrimers can be considered to be governed by intramolecular chemical reactions, albeit ones in relatively viscous media with limited mobility. Thus, classical factors that are known to exert important effects on the course, rate and outcome of chemical reactions, also need to be explicitly considered in the study and 


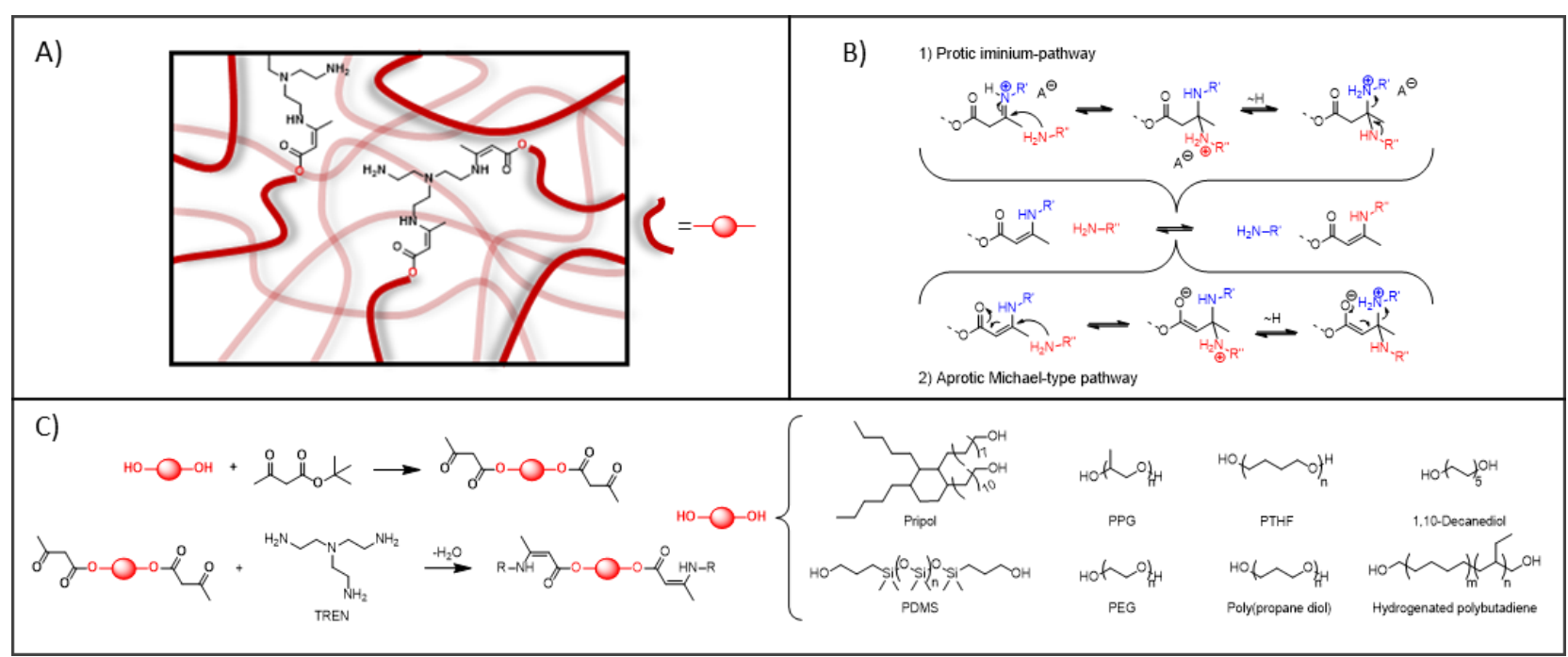

Figure 1 A) Schematic representation of a vinylogous urethane network. B) Transamination mechanisms ${ }^{33}$, 1) protic pathway via iminium-state, 2) aprotic pathway via Michael-type addition. C) Schematic representation of an acetoacetylation of a diol and network formation (left) and the respectively investigated diols (right).

design of vitrimers. For example, it is common knowledge that the choice of a solvent allows control over several characteristics of a reaction such as the reaction rate, activation energy, the product and reagent solubility, the selectivity and yield. ${ }^{26}$ Within classical transition state theory, a solvent influences these reaction parameters via changing the thermodynamic landscape, or the potential energy surface (PES) of the ideal gas phase, through varying intermolecular interactions such as London dispersion forces, ionic or dipolar interactions, hydrogen bonding interactions, and the hydrophobic effect. All of these effects are surely not limited to reactions of small molecules in solvents and will be important for all reactions occurring within condensed phases, especially with cross-linked macromolecular matrices, which are very far located from ideal gas phase conditions.

Within a rearranging polymer matrix, the concentration or rather availability of reactive species for a bimolecular event, which is a necessary condition for every possible exchange mechanism, will critically depend on the polymer architecture and chemical make-up. Such effects have been documented in polymer synthesis, such as in the preparation of single-chain nanoparticles ${ }^{27,} 28$ or loop structures ${ }^{29}$, which only work in highly diluted systems. For CANs and vitrimers, however, such effects have been less well studied so far, and also appear to be more challenging.

Given the above analysis, one can hypothesise that solvent effects will be quite important for vitrimer materials. The chemical structure of the matrix can certainly interact and (de)stabilise either the transition state or the chain dynamics, leading to significant deviations from the same bimolecular reactions in ideal gas phase or ideal solution phase chemistry. In a first approach, in a matrix where every cross-linking juncture is chemically exchangeable, a given cross-linking density can be thought to represent a concentration, with the probability of productive exchanges to depend at least quadratically with this concentration (for a bimolecular rate determining step). Therefore, changing the length of the spacer molecules between the dynamic bonds can be interpreted as 'adding more solvent' to dilute the concentration of reactants. In practice, the situation may be more convoluted. Longer polymer chains will have a higher chain end mobility, possibly giving a more dynamic network. Moreover, the situation can be more complicated even without such effects, as many reactions also depend on other species such as the presence of free chain ends or a catalytic species.

Although remarkable changes in activation energy and relaxation times have been described numerous times in the comparison between vitrimers ${ }^{25}$ or between vitrimers and the small molecule chemical equivalents of the exchange reaction, it is clear that possible matrix effects on the exchange reactions of vitrimers seem to have been somewhat overlooked until now, and that fundamental studies within such phenomena is still lacking. Here, we report a systematic design and analysis of a range of vitrimer materials, explicitly aiming to probe the influence of the surrounding matrix on dynamic exchange reactions. For that purpose, the transamination of vinylogous urethanes (VU), a relatively well-studied vitrimer chemistry both within and beyond our own research group, was selected as dynamic exchange reaction platform (Figure 1A). ${ }^{5}, 30-36$ Additionally, in order to investigate the effects of the crosslinking density (interpreted as concentration), different molecular weights of macromolecular monomers were studied. Conveniently, the different polymer matrices could be obtained starting from a wide range of commercially available diols (Figure 1C, right panel) and a commercially available trifunctional amine. 


\section{Results and discussion}

Within this study, the expected effects of the polymer matrix are probed by comparing the viscoelastic and rheological properties of fourteen different diol-derived vitrimers with backbones ranging from silicone (polydimethylsiloxane, PDMS), to polyethers (polytetrahydrofuran (PTHF), polyethylene glycol (PEG) and polypropylene glycol (PPG)) as well as more hydrophobic backbone spacers (1,10-decanediol, Pripol 2033) (Figure 1C). The systematic evaluation of the influence of the cross-link density on the stress relaxation was focused on two different polyethers, readily available in different molecular

A)

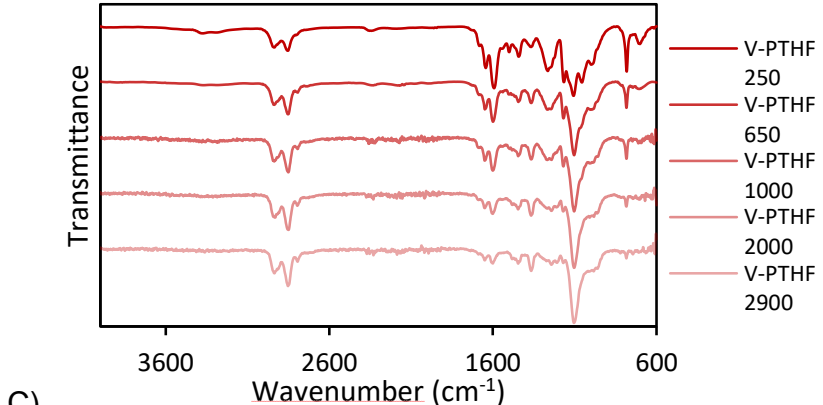

C)

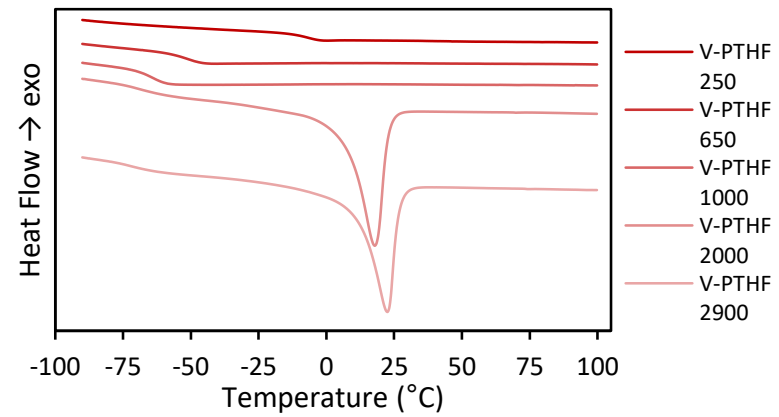

based on PTHF with a molecular weight of $250 \mathrm{~g} \cdot \mathrm{mol}^{-1}$ is referred to as $\mathrm{V}-\mathrm{PTHF}_{250}$. Additionally, when a value of molecular weight is mentioned, it refers to the average molecular weight $\left(M_{n}\right)$ of the commercial diols. No other formulations will be discussed herein, although in principle many more variations are possible.

\section{Network characterization}

As a first step of the material characterization, the network formation was analysed. The full transformation of the acetoacetates into vinylogous urethane moieties was confirmed by ATR-FTIR, showing the absence of the acetoacetate vibration

B)
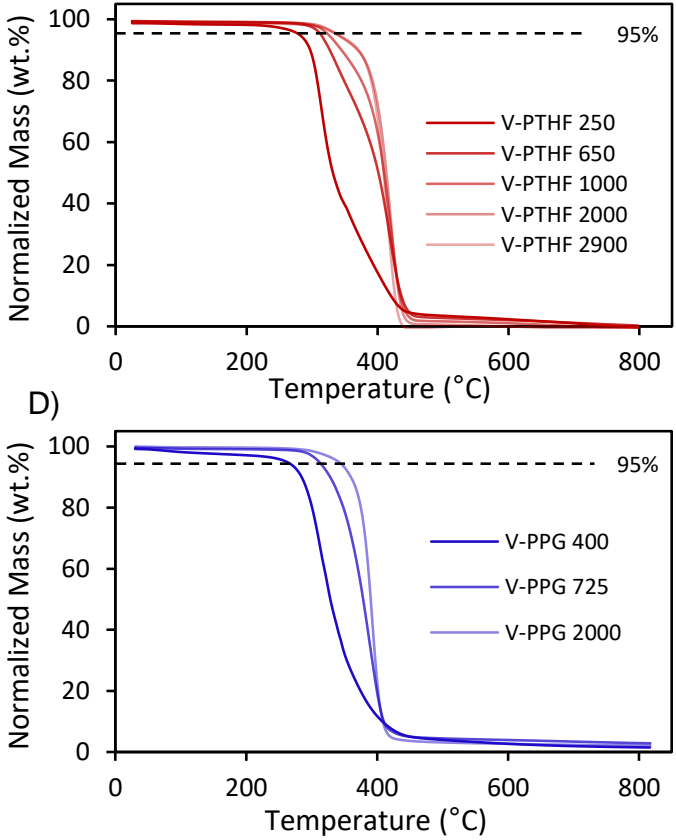

Figure 2 A) AT-FTIR spectrum of the different PTHF vitrimers. C) DSC thermograms of the different PTHF vitrimers with a heating rate of 10 K.min ${ }^{-1}$. B \& D) TGA measurements of the different (B) PTHF and (D) PPG vitrimers obtained from a temperature ramp from 25 to $800^{\circ} \mathrm{C}$ at $10 \mathrm{~K} . \mathrm{min}^{-1} \mathrm{under} \mathrm{N}_{2}$ atmosphere.

weights: PTHF (Mn: 250, 650, 1000, 2000, and 2900 g.mol ${ }^{-1}$ ) and PPG ( $\mathrm{M}_{\mathrm{n}}$ : 400, 725 and $\left.2000 \mathrm{~g} \cdot \mathrm{mol}^{-1}\right)$. Simple acetoacetylation of these different commercially available diols generates the required bis-acetoacetate monomers (Figure 1C, left panel). To achieve this, a high yielding solvent-free procedure, recently introduced by our group, was utilised. ${ }^{37}$

By combination with a trifunctional primary amine, tris(2aminoethyl)amine (TREN) as cross-linker, a range of VU vitrimer networks were obtained, having a 5 mol.\% excess of primary amines as reactive chain ends. This ratio fixes the relative concentration of free amine versus VU moieties, and was previously established by our group to provide sufficiently abundant nucleophilic units to allow rapid exchange via a transamination pathway (Figure 1B) in a reproducible manner. ${ }^{5}$, 35,37 In order to keep the variable parameters of the system low, this relative molar amount of pendent primary amine groups was kept constant in all formulations. Throughout the remainder of this paper, the obtained VU vitrimers are abbreviated according to the used diol, which represents the main spacer between the cross-linking points, e.g. a vitrimer band at $1720 \mathrm{~cm}^{-1}$ and the presence of the characteristic vinylogous urethane vibration bands at $1580 \mathrm{~cm}^{-1}$ and $1640 \mathrm{~cm}^{-1}$ (see Figure 2A for the PTHF vitrimer spectra; other vitrimer spectra are provided in the ESI Figure S1 and S2). ${ }^{5}$ As can be expected, the relative intensity of the vinylogous urethane characteristic vibration decreases with respect to the other backbone signals, as the molar weight of the PTHF macromonomer increases from 250, to $650,1000,2000$, and 2900 g.mol${ }^{-1}$ (Figure 2A). Thus, the cross-link density can be assessed spectroscopically. A similar trend in IR spectra was also observed for the investigated PPG-based vitrimers ( $M_{n}$ PPG: 400, 725 and 2000 g. mol-1) (Figure S1).

Secondly, the efficiency of network formation was assessed via swelling and solubility experiments. In this context, tetrahydrofuran (THF) was selected as the most suitable solvent because of the good swelling properties observed at room temperature for all matrices (Table 1 ). Indeed, the resultant swelling degrees range from at least $100 \mathrm{wt} . \%$ for PEG to almost 400 wt.\% for PDMS, as reported in Table 1. 
In Table 1, a clear effect of the molecular weight of the backbone diols on the swelling properties can be observed, which is perfectly in line with expectations. Higher molecular weights of the prepolymers indeed result in increasing swelling degrees, again confirming the decrease of the cross-linking Table 1 Molecular weight $\left(\mathrm{M}_{\mathrm{n}}\right)$ of the investigated diols, swelling ratio and soluble fraction, thermal properties, characteristic relaxation time, and activation energies, of the investigated vitrimers. density for both investigated polyethers, PTHF and PPG (see first eight entries of Table 1). Besides the high swelling degrees obtained for each of the networks, the determined soluble fraction remained below 5 wt.\%, showing a good network formation for all investigated vitrimers (Table 1 ).

\begin{tabular}{|c|c|c|c|c|c|c|c|c|}
\hline Matrix & $\begin{array}{c}\text { Mn diol } \\
\left(\text { g.mol }{ }^{-1}\right) \\
\end{array}$ & $\begin{array}{c}\text { Swelling } \\
\text { Ratio }^{\text {a }}(\%) \\
\end{array}$ & $\begin{array}{c}\text { Soluble } \\
\text { Fraction }^{\text {b }}(\%)\end{array}$ & $\begin{array}{l}\mathrm{T}_{\mathrm{g}}^{\mathrm{c}} \\
\left({ }^{\circ} \mathrm{C}\right) \\
\end{array}$ & $\begin{array}{l}\mathrm{T}_{\mathrm{d} 5 \%}{ }^{\mathrm{d}} \\
\left({ }^{\circ} \mathrm{C}\right) \\
\end{array}$ & $\begin{array}{l}\tau_{140^{\circ} \mathrm{C}}^{*} \\
(\mathrm{~min}) \\
\end{array}$ & $\begin{array}{c}\mathrm{E}_{\mathrm{a}}(\mathrm{I})^{\mathrm{e}} \\
\left(\mathrm{kJ} . \mathrm{mol}^{-1}\right) \\
\end{array}$ & $\begin{array}{c}E_{a}(\mathrm{II})^{f} \\
\left(\mathrm{~kJ} . \mathrm{mol}^{-1}\right)\end{array}$ \\
\hline \multirow{5}{*}{ PTHF } & 250 & $145 \pm 2$ & $1.9 \pm 0.6$ & -8 & 280 & 7 & $75 \pm 2$ & $212 \pm 3$ \\
\hline & 650 & $167 \pm 2$ & $0.9 \pm 0.3$ & -50 & 315 & 51 & $68 \pm 2$ & $292 \pm 88$ \\
\hline & 1000 & $213 \pm 1$ & $2.4 \pm 0.5$ & -63 & 325 & 69 & $101 \pm 11$ & $342 \pm 135$ \\
\hline & 2000 & $305 \pm 4$ & $3.4 \pm 0.3$ & -65 & 340 & 94 & $125 \pm 3$ & $311 \pm 33$ \\
\hline & 2900 & $292 \pm 6$ & $2.9 \pm 0.2$ & -67 & 340 & 231 & $149 \pm 10$ & $403 \pm 60$ \\
\hline \multirow{3}{*}{ PPG } & 400 & $223 \pm 2$ & $3.1 \pm 0.2$ & -8 & 260 & 46 & $76 \pm 5$ & $261 \pm 45$ \\
\hline & 725 & $271 \pm 3$ & $2.4 \pm 0.1$ & -37 & 310 & 43 & $105 \pm 3$ & $406 \pm 17$ \\
\hline & 2000 & $368 \pm 4$ & $1.1 \pm 0.4$ & -55 & 340 & 55 & $71 \pm 4$ & $141 \pm 22$ \\
\hline PEG & 400 & $100 \pm 6$ & $1.6 \pm 0.2$ & -16 & 300 & 48 & $94 \pm 3$ & $521 \pm 92$ \\
\hline $\mathrm{PPD}^{\#}$ & 250 & $153 \pm 3$ & $1.9 \pm 0.1$ & -8 & 295 & 2 & $93 \pm 3$ & -- \\
\hline Pripol & 537 & $155 \pm 4$ & $0.9 \pm 0.5$ & -6 & 315 & 9 & $68 \pm 1$ & -- \\
\hline PDMS & 5500 & $375 \pm 1$ & $4.9 \pm 0.1$ & ${ }^{-}$ & 345 & 32 & $117 \pm 3$ & -- \\
\hline $\operatorname{Dec}^{\#{ }^{\prime}}$ & 174 & $101 \pm 1$ & $0.8 \pm 0.4$ & 31 & 295 & 56 & $97 \pm 6$ & -- \\
\hline HPB & 3100 & $256 \pm 3$ & $2.3 \pm 0.1$ & -47 & 370 & 70 & $119 \pm 2$ & $295 \pm 25$ \\
\hline
\end{tabular}

a Determined after $24 \mathrm{~h}$ in THF via equation (2); ${ }^{\mathrm{b}}$ Determined via equation (1) after $24 \mathrm{~h}$ in THF and dried for $24 \mathrm{~h}$ in a vacuum oven at $40{ }^{\circ} \mathrm{C}$. ${ }^{\mathrm{c}} \mathrm{Glass}$ transition temperature $\left(T_{g}\right)$ determined by differential scanning calorimetry (DSC) from the second heating cycle with a heating and cooling rate of $10 \mathrm{~K}$. min ${ }^{-1}$; ${ }^{d}$ Temperature at which a weight loss of $5 \%$ is observed by thermogravimetric analysis (TGA) in a temperature ramp from 25 to $800{ }^{\circ} \mathrm{C}$ at $10 \mathrm{~K}$. $\mathrm{min}^{-1}$ under $\mathrm{N}_{2}$ atmosphere; ${ }^{\mathrm{e}}$ The low temperature region $\left(110{ }^{\circ} \mathrm{C}\right.$ to $140{ }^{\circ} \mathrm{C}$ if an $\mathrm{E}_{\mathrm{a}}(\mathrm{II})$ is present) otherwise the full temperature region; ${ }^{\mathrm{f}}$ The high temperature region $\left(145^{\circ} \mathrm{C}\right.$ or $150{ }^{\circ} \mathrm{C}$ up to $\left.160{ }^{\circ} \mathrm{C}\right) ;{ }^{\# P o l y}(\mathrm{propane}$ diol) $(\mathrm{PPD})$; \#'1, 10-Decanediol (Dec)

\section{Thermal properties}

After having verified the network formation, the thermal properties of the created vitrimers were also investigated. Glass transition temperatures $\left(\mathrm{T}_{\mathrm{g}}\right)$ were determined via differential scanning calorimetry (DSC) and degradation temperatures after 5 wt.\%. loss $\left(T_{d 5 \%}\right)$ were determined for each network via thermogravimetric analysis (TGA), as displayed in Table 1.

In addition to previously observed trends with respect to increased molar masses and resulting decreased cross-linking density, trends could be detected when looking at the evolution of the $T_{g}$. Indeed, the $T_{g}$ values of the PTHF-based networks decreased significantly from $-8^{\circ} \mathrm{C}\left(\mathrm{V}-\mathrm{PTHF}_{250}\right)$ to $-50^{\circ} \mathrm{C}(\mathrm{V}$ $\mathrm{PTHF}_{650}$ ), levelling off at $-63^{\circ} \mathrm{C},-65^{\circ} \mathrm{C}$ and $-67^{\circ} \mathrm{C}$ with chain lengths above 1000 g.mol-1 (Table 1 and Figure 2B). A similar trend was observed for the PPG-based networks where the $T_{g}$ decreased from $-8{ }^{\circ} \mathrm{C}\left(\mathrm{V}-\mathrm{PPG}_{400}\right)$ to $-55^{\circ} \mathrm{C}\left(\mathrm{V}-\mathrm{PPG}_{2000}\right.$ ) (Table 1 and Figure S3). Overall, the obtained materials displayed a $\mathrm{T}_{\mathrm{g}}$ range of $-120^{\circ} \mathrm{C}\left(\mathrm{V}-\mathrm{PDMS}_{5000}\right)$ to $31^{\circ} \mathrm{C}(\mathrm{V}-\mathrm{Dec})$ (Figure S4-S7).

Furthermore, all networks displayed good thermal stability with $\mathrm{T}_{\mathrm{d} 5 \%}$ of around $300{ }^{\circ} \mathrm{C}$, with the lowest being $260^{\circ} \mathrm{C}$ for $\mathrm{V}-\mathrm{PPG}_{400}$ (Table 1). Additionally, it was noticed that by increasing the molecular weight of the respectively investigated polyether backbones, the thermal stability improved. For instance, PTHF- based vitrimers exhibited $\mathrm{T}_{\mathrm{d} 5 \%}$ starting from $280{ }^{\circ} \mathrm{C}\left(\mathrm{V}-\mathrm{PTHF}_{250}\right)$ up to $340{ }^{\circ} \mathrm{C}$ (V-PTHF 2000 and $\mathrm{V}-\mathrm{PTHF}_{2900}$ ) (Table 1 and Figure 2B). Again, a similar trend can be observed for PPG-based vitrimers (Table 1 and Figure 2D). The shortest representatives of a type of materials typically ( $\mathrm{V}-\mathrm{PTHF}_{250}$ and $\mathrm{V}-\mathrm{PPG}_{250}$ ) show the earliest onset-temperature in a TGA temperature ramp. Interestingly, the degradation temperature appeared to level off at $340{ }^{\circ} \mathrm{C}$ both for V-PTHF and V-PPG. Additionally, but as expected, a clear influence of the matrix on the degradation temperature could also be observed, as the vitrimer based on hydrogenated polybutadiene (HPB, $M_{n}=3100 \mathrm{~g} \cdot \mathrm{mol}^{-1}$ ) displayed a higher $\mathrm{T}_{\mathrm{d} 5 \%}$ of $370{ }^{\circ} \mathrm{C}$, while having a similar molecular weight compared to $\mathrm{V}-\mathrm{PTHF}_{2900}$ (Figure S8). Indeed the thermal degradation of polymers is influenced by a large amount of factors, such as bond energies, presence of functional groups, degree of cross-linking and molecular weight. ${ }^{38}$ Therefore, the increase in thermal stability of the PTHF and PPG vitrimers, with increasing molecular weight of the diol, can be explained by both the increased thermal stability of the starting diol (Figure S9-S11) and by a lower amount of 
A)
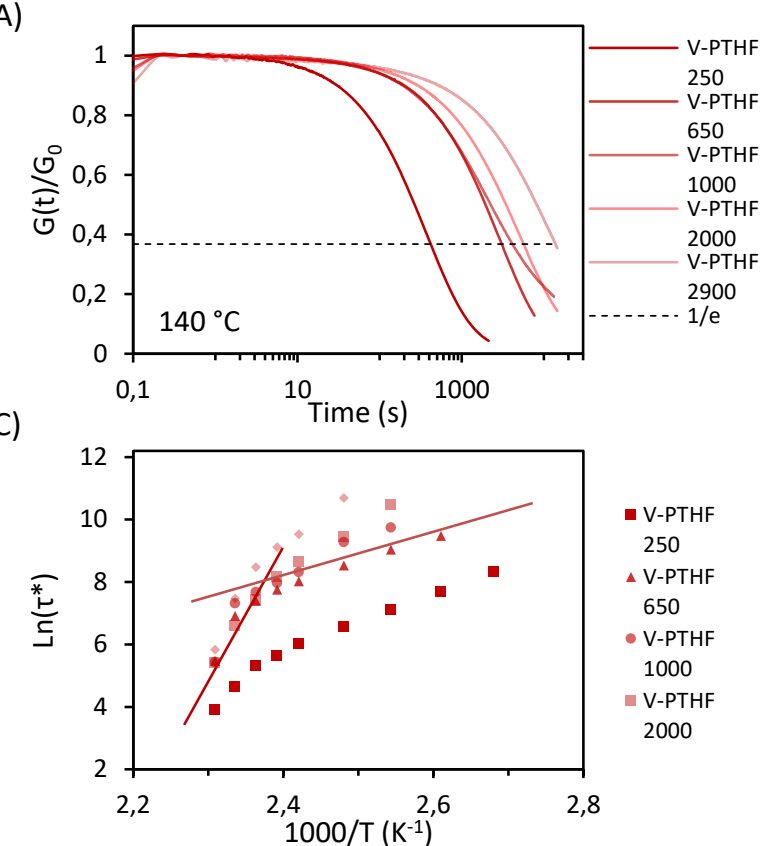

B)

D)
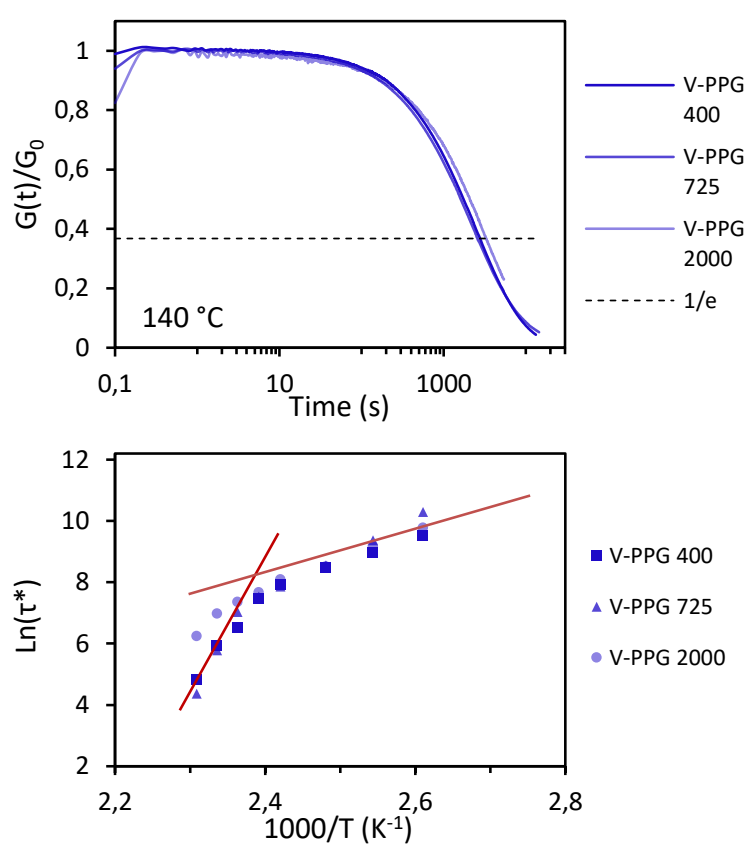

Figure 3 A \& B) Stress relaxation experiments at $140{ }^{\circ} \mathrm{C}$ of PTHF and PPG vitrimers, respectively. The black dotted line repres ents $\mathrm{G}(\mathrm{t}) / \mathrm{G}_{0}=1 / \mathrm{e}$, which defines the characteristic relaxation time $\tau^{*}$. C \& D) Arrhenius plots of PTHF and PPG vitrimers, respectively. The red line indicates the higher temperature response that correlates with the Michael-type pathway while the orange line indicates the lower temperature response that correlates with an iminium pathway (see Fig. 1b).

functional groups. Fewer dynamic bonds represent less reactive functional moieties, which could induce degradation processes. Nonetheless, as demonstrated by our previous work, polyether based vitrimeric materials are sufficiently thermally stable to be used at the respective processing temperatures, which are well below the respective degradation onset-temperatures. ${ }^{35}$

In a final step, the storage moduli of the V-PTHF and V-PPG materials with different molecular weights, obtained via time sweep experiments using a rheometer, were compared (Figure S12 and S13). As expected, the trend of decreasing storage modulus with increasing molecular weight was observed, further confirming the difference in cross-link density.

\section{Viscoelastic behaviour characterization}

After analysis of the network formation and thermal properties, the viscoelastic properties of the obtained VU vitrimers were investigated via stress relaxation experiments. It is important to note again that all these vitrimers have almost the same dynamic VU bonds, with the same relative amount of free amines, and only differ in the chemical structure and length of the backbone spacers. These measurements thus allowed the comparison of the dynamic exchange characteristics, i.e. relative relaxation rates and activation energies of the investigated polymeric matrices. As mentioned before, it is so far common practice in vitrimer studies to compare activation energies from model studies or other materials with the same exchange chemistry, without explicitly taking possible matrix effects into account. 5, 33, 35, 37, 39-41 However, it can be expected that such effects are real and possibly significant, leading us to conduct this systematic investigation.
Firstly, the influence of the spacer length between VU moieties and thus the cross-linking density, should be considered. Looking at the obtained relaxation times in Table 1 for different PTHF or PPG spacer lengths at $140^{\circ} \mathrm{C}$, it can be noticed that both backbones show a tendency of decreasing relaxation rates with decreased cross-linking density (Table 1 and Figure $3 \mathrm{~A}$ ), albeit much more pronounced for PTHF, where an acceleration factor of more than 10 can be seen. This increase could potentially be explained by a concentration effect as described above, i.e. a lower concentration of dynamic bonds could result in a lower probability of effective exchange and explain the observed slower exchange kinetics. However, this explanation is certainly not transposable to PPG-based vitrimers within the studied temperature and cross-linking density windows (Table 1 Figure 3B). There, spacer length effects seem to be only marginal in terms of relaxation times, and even a small rate acceleration can be seen going from V-PPG-400 to V-PPG-725. The same convergence of rheological data even seems to manifest itself at every temperature (see Figure 3D). Seemingly, for the PPG matrix, the molecular weight of the macromonomers does not influence the exchange kinetics to the same extent as for PTHF-based vitrimers (see Figure $3 \mathrm{C}$ ), although this profile could also be explained by contradicting effects that cancel each other out. These results give a first strong indication that assessing matrix effects in vitrimers, although certainly real and significant, are also far from trivial.

Beside the absolute stress relaxation times, as a direct measure of the exchange rates, it is also important to mention that the activation energies seem to be affected by the difference in spacer lengths between cross-links. However, in this situation, 
A)

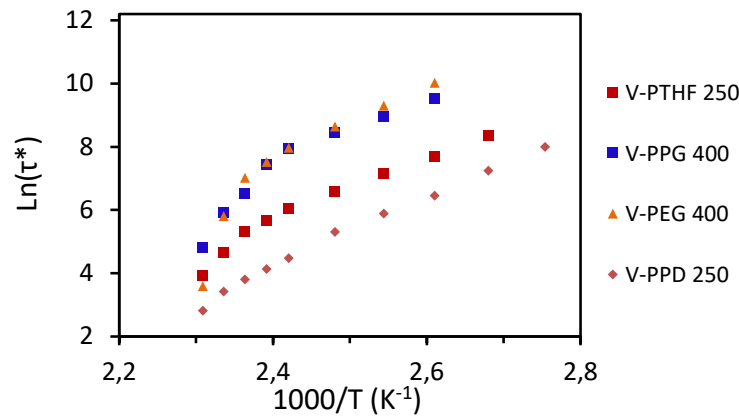

B)

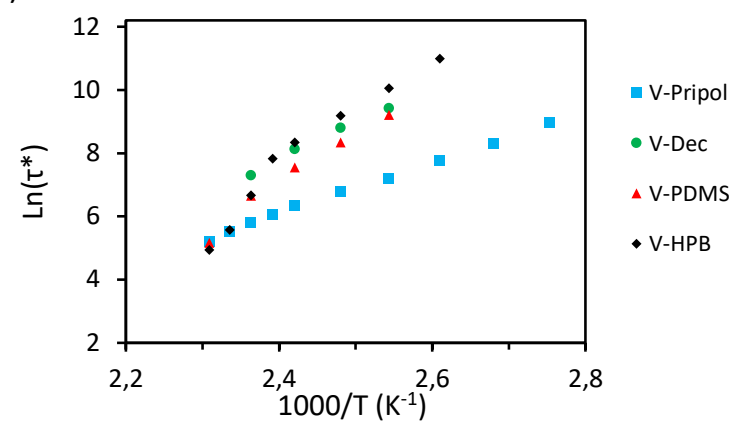

activation energy data are complicated by a previously reported dual temperature response that can give deviations in temperature windows that are spanning two different exchange regimes (Figure $3 \mathrm{~A}$ and 3B). 35,37 This dual temperature response has been previously rationalised by the possibility for the transamination of vinylogous urethanes to occur via either an ionic iminium pathway involving a protonated amine as a reactive species or catalyst (with a lower temperature response) or a Michael-type pathway involving the neutral ground states of the reactive species (higher activation energy, but a pathway not requiring a pre-existing protonated species) (Figure 1B).

When fitting only the linear regions of the rheology plots, still variations in activation energies in both temperature response regions were obtained depending on the spacer length (Table 1). However, no clear trend, such as increasing activation energies with higher molecular weight, could be derived from these studies. Nevertheless, due to the observed changes in activation energies with molecular weight, the cross-link density should not be ignored as a parameter when comparing those activation energies.

Secondly, to investigate the influence of the matrix, the different polyether based vitrimers (V-PTHF, V-PPG, V-PEG and V-PPD), with relatively similar molecular weights of the diol macromonomer, were compared to each other. Noticeably, the dual-temperature response could be detected for most, but not all, of the herein investigated polyether-based vitrimers (Table 1 and Figure 4A). Indeed, this dual temperature behaviour was apparent in all PTHF and PPG vitrimers, and also in $\mathrm{V}-\mathrm{PEG}_{400}$ in variably pronounced states but could not be detected for V-PPD 250 (Figure 4A). This indicates again that the stabilization of the Michael-pathway is both matrix and molecular weight dependent. Since the dual-response was not observed for all materials, the focus of the rest of our comparative study was mostly placed towards the lowactivation energy region (i.e. corresponding to the iminium pathway). In this region, activation energies of around 75 kJ. mol-1 were observed for more hydrophobic backbones (i.e. for $\mathrm{V}-\mathrm{PTHF}_{250}$ and $\mathrm{V}-\mathrm{PPG}_{400}$, respectively) while a value of $94 \mathrm{~kJ} . \mathrm{mol}^{-1}$ was obtained for a more hydrophilic one (V-PEG$\left.{ }_{400}\right)$ (Table 1).

When comparing different backbones, not only the activation energies can be seen to depend on the polymer matrix, but also the stress relaxation times are strongly affected by the polymer matrix. Here, $\mathrm{V}-\mathrm{PPD}_{250}$ displayed an exchange rate resulting in a characteristic relaxation time of only 2 minutes at $140^{\circ} \mathrm{C}$, whereas the determined relaxation time at $140^{\circ} \mathrm{C}$ of V-Dec was more than 20 times slower, at 56 minutes, despite having similar spacer lengths and having a similar activation energy (93 vs $97 \mathrm{~kJ}^{\mathrm{mol}}{ }^{-1}$ ) in this temperature region. As solvatation is less important in the iminium pathway, and given the difference in $\mathrm{T}_{\mathrm{g}}$, the most likely explanation here would indeed be chain end mobility, leading to an increased availability or 'effective concentration' of reactive moieties, without affecting the temperature-dependent kinetic parameters (i.e. the activation energy).

Interestingly, many of the more hydrophobic backbones (PDMS, pripol and decanediol) seem to suppress the occurrence of a regime related to a Michael pathway, showing linearity over the entire temperature window, corresponding to an exclusive iminium pathway. Only the highly hydrophobic matrix V-HPB 3100 exhibited the dual temperature response that was observed for the polyethers (Figure $4 \mathrm{~B}$ ). A rationale here can be found in the gradual inhibition of the iminium pathway, as the matrix become more hydrophobic and reactive ammonium species are diluted. For the HPB-vitrimer, the normal pathway is likely suppressed so much that it reveals the 'background' Michael pathway.

Such intricate analyses again highlight the complexity of the influence of the chemical nature of the surrounding matrix on the dynamic exchange. Overall, quite significantly different relaxation times were obtained for these materials (Table 1 ). Despite the difference in the molecular weight of the starting diols, these results again strongly suggest that the nature of the matrix has a clear influence on the viscoelastic characteristics of vitrimers. In any case, it appears that specifically for vinylogous urethane-based vitrimers, most polyether backbones lead to a dual-temperature response with varying high temperature dependencies, whereas more hydrophobic aliphatic counterparts usually exhibit a single temperature dependency, unless cross-links are diluted more by longer spacers. 


\section{Experimental}

\section{Materials}

1,10-Decanediol (98\%), bis(hydroxyalkyl)-terminated polydimethylsiloxane (PDMS, $M_{n}=5600 \mathrm{~g} \cdot \mathrm{mol}^{-1}$ ), polyethylene glycol (PEG $M_{n}=400 \mathrm{~g} \cdot \mathrm{mol}^{-1}$ ), polypropylene glycol (PPG, $M_{n}=$ 400, 725 and 2000 g.mol-1), polytetrahydrofuran (PTHF, $M_{n}=$ 250, 650, 1000, 2000 and 2900 g.mol $\left.{ }^{-1}\right)$, tert-butyl acetoacetate (TBAA, >98\%) and tris(2-aminoethyl)amine (TREN, 96\%) were purchased from Sigma Aldrich and used without further purification. Tetrahydrofuran (THF) was purchased from Acros Organics. Hydrogenated polybutadiene (HPB, Krasol LBH-P 3000, $\left.M_{n}=3100 \mathrm{~g} \cdot \mathrm{mol}^{-1}\right)$ was purchased from Cray Valley. Polypropanediol (PPD, $\mathrm{M}_{\mathrm{n}}=250 \mathrm{~g} \cdot \mathrm{mol}^{-1}$ ) was kindly provided by WeylChem Innotec. Pripol 2033 was kindly provided by Croda.

\section{Instrumentation}

Nuclear magnetic resonance (NMR) spectra were recorded on a Bruker Avance Ultrashield $300 \mathrm{MHz}$ or a Brucker Avance II 400 $\mathrm{MHz}$ spectrometer. Deuterated DMSO or chloroform was used as solvent. Coupling constants and chemical shifts are given in hertz $(\mathrm{Hz})$ and parts per million $(\mathrm{ppm})$, respectively. The experimental conditions for recording NMR spectra were as followed: ${ }^{1} \mathrm{H}$ : flip angle: $30^{\circ}$; acquisition time: $4.1 \mathrm{~s}$; pulse delay: $7.75 \mu \mathrm{s}$; number of scans: 16; spectral window: $8 \mathrm{kHz}$.

Infrared (ATR-FTIR) spectra were measured using a PerkinElmer Spectrum1000 FTIR infrared spectrometer with a diamond ATR probe.

Thermogravimetric analyses (TGA) were performed with a Mettler Toledo TGA/ SDTA851e instrument under nitrogen atmosphere at a heating rate of $10 \mathrm{~K} \cdot \mathrm{min}^{-1}$ from $25^{\circ} \mathrm{C}$ to $800{ }^{\circ} \mathrm{C}$ for a temperature ramp.

Differential scanning calorimetry (DSC) analyses were performed with a Mettler Toledo instrument 1/700 under nitrogen atmosphere at a heating rate of $10 \mathrm{~K} \cdot \mathrm{min}^{-1}$.

Rheology experiments were performed on an Anton Paar MCR 302. The experiments were performed using a parallel plate geometry with $8 \mathrm{~mm}$ sample disks. Unless specified, the experiments were performed using a normal force of $1 \mathrm{~N}$, an oscillating frequency of $1 \mathrm{rad}^{-1}$ and a strain of $1 \%$. For all rheology experiments, the applied stress was comprised in the linear viscoelastic region at the measured temperatures. For amplitude sweep experiments, the strain was varied from 0.01 to $100 \%$. For stress relaxation experiments, a strain of $1 \%$ was applied to the material and the relaxation modulus $(G(t))$ was followed over time at a constant temperature.

Reprocessability. To reprocess the network, the polymer was broken into pieces and placed into a rectangular mould (A: $70 \mathrm{~mm} \times 40 \mathrm{~mm} \times 2 \mathrm{~mm}$; B: $30 \mathrm{~mm} \times 15 \mathrm{~mm} \times 2 \mathrm{~mm}$ ) for compression moulding. This assembly was placed in a $150{ }^{\circ} \mathrm{C}$ preheated compression press for 2 min under 0.5 metric tons of pressure. Then the pressure was increased to 2 tons and kept constant for an additional 3 to $43 \mathrm{~min}$. After 5 to $45 \mathrm{~min}$ of pressing in total, the mould was cooled down for $30 \mathrm{~min}$ and the sample was removed from the metal sheet with a razor blade. The temperature and pressing time have been adjusted according to the material behaviour. For instance: $\mathrm{PPG}_{400}$-based vitrimers with $5 \mathrm{~mol} . \%$ excess amine moieties were processed for $15 \mathrm{~min}$ in total at $150^{\circ} \mathrm{C}$, whereas $\mathrm{PPG}_{2000}$-based networks were processed for $30 \mathrm{~min}$ at $150^{\circ} \mathrm{C}$.

Solubility. Solubility tests were carried out in $3 \mathrm{~mL}$ of THF with vacuum dried samples of $6 \mathrm{~mm}$ diameter, 1.5 to $2 \mathrm{~mm}$ thickness, and a mass of 40 to $60 \mathrm{mg}$. Those tests were performed for $24 \mathrm{~h}$ at room temperature. Then, the solvent was removed, and the samples were dried under vacuum for two days at $40^{\circ} \mathrm{C}$. The soluble fraction was calculated using equation (1), while the swelling ratio was calculated using equation (2).

$$
\begin{aligned}
& \text { Soluble fraction }(\%)=\frac{m_{i}-m_{d}}{m_{i}} \\
& \text { Swelling ratio }(\%)=\frac{m_{s}-m_{i}}{m_{i}}
\end{aligned}
$$

with $m_{i}, m_{s}$ and $m_{d}$ being the initial, swollen and dry mass, respectively.

\section{Monomer and network synthesis}

Monomer synthesis. 1 equivalent of diol and 2.1 equivalents of tert-butyl acetoacetate were added in a flask. The viscous mixture was heated for $60 \mathrm{~min}$ at $130{ }^{\circ} \mathrm{C}$, and tert-butanol product was continuously removed by vacuum distillation throughout the reaction. When the temperature of the still head dropped to $40^{\circ} \mathrm{C}$ and tert-butanol condensation stopped, the unreacted tert-butyl acetoacetate was removed by distillation at $130{ }^{\circ} \mathrm{C}$ under 2 mbar pressure.

Example with the synthesis of polypropylene glycol bisacetoacetate (PPG $400-A A)$ : Polypropylene glycol $\left(M_{\mathrm{n}} \approx\right.$ $\left.400 \mathrm{~g} . \mathrm{mol}^{-1}, 120 \mathrm{~g}, 3.0 \times 10^{-1} \mathrm{~mol}\right)$ and tert-butyl acetoacetate $\left(100 \mathrm{~g}, 6.32 \times 10^{-1} \mathrm{~mol}\right)$ were added in a flask. The viscous mixture was heated for $60 \mathrm{~min}$ at $130^{\circ} \mathrm{C}$, and tert-butanol product was continuously removed by vacuum distillation throughout the reaction. When the temperature of the still head dropped to $40{ }^{\circ} \mathrm{C}$ and tert-butanol condensation stopped, the unreacted tert-butyl acetoacetate was removed by distillation at $130{ }^{\circ} \mathrm{C}$ under 2 mbar pressure. Yield $=95 \%$.

${ }^{1} \mathrm{H}$ NMR (300 MHz, DMSO-d 6 , $\delta$ ppm): 0.98-1.11 $\left(-\mathrm{CH}_{2}-\mathrm{CH}\left(\mathrm{CH}_{3}\right)-\right.$ ), 1-1.12 $\left(-\mathrm{CH}_{2}-\mathrm{CH}\left(\mathrm{CH}_{3}\right)-\mathrm{O}(\mathrm{C}=\mathrm{O})-\right), 2.14-2.22\left(-\mathrm{CH}_{2}-(\mathrm{C}=\mathrm{O})-\mathrm{CH}_{3}\right)$, 3.20-3.70 (- $\mathrm{CH}_{2}-\mathrm{CH}\left(\mathrm{CH}_{3}\right)^{-}, \quad-\mathrm{CH}_{2}-\mathrm{CH}\left(\mathrm{CH}_{3}\right)-\mathrm{O}-(\mathrm{C}=\mathrm{O})-$ and $\left(-\mathrm{CH}_{2}-\right.$ $\left.(\mathrm{C}=\mathrm{O})-\mathrm{CH}_{3}\right), 4.83-5.03\left(-\mathrm{CH}_{2}-\mathrm{CH}\left(\mathrm{CH}_{3}\right)-\mathrm{O}-(\mathrm{C}=\mathrm{O})-\right)$.

Network synthesis. In order to obtain vitrimer networks with 5 mol.\% pendent primary amines, the calculated amount of bisacetoacetate (macro)monomer (AA) was combined with tris(2aminoethyl)amine (TREN) (see equation (3)) in a polypropylene vial and mixed using a DAC $150.1 \mathrm{FVZ}$ speed mixer (typical conditions of mixing: 2 min with a speed of $2500 \mathrm{rpm}$ ).

$$
n_{\text {TREN }}=\frac{n_{\text {bisacetoacetate }} * 2}{3} * 1.05
$$


Example of network formation using $P P G_{400}-A A: P P G_{400}-A A\left(M_{n}\right.$ $\approx 570 \mathrm{~g} \cdot \mathrm{mol}^{-1}, 10 \mathrm{~g}, 17.54 \times 10^{-3} \mathrm{~mol}$ ) and (TREN, $1.796 \mathrm{~g}$, $12.28 \times 10^{-3} \mathrm{~mol}$ ) were mixed in a $12 \mathrm{~mL}$ polypropylene vial using the above-mentioned speed mixer. Then, the cup was placed in an oven at $80^{\circ} \mathrm{C}$ for up to $4 \mathrm{~h}$ to complete the network formation. Hereafter, the polypropylene vial was broken, and the network was cured and dried overnight at $70^{\circ} \mathrm{C}$ under vacuum. Finally, the sample was cut into pieces of around $1 \mathrm{~g}$, and pressed separately in steel moulds, following the aforementioned reprocessability procedures.

\section{Conclusions}

Herein, different vinylogous urethane vitrimers were synthesised based on varying chain length and hydrophobicity of spacing backbones between dynamic moieties. These materials were used to investigate the influence of the matrix and the cross-linking density on the viscoelastic behaviour of vitrimers, with respect to stress relaxation. The obtained vitrimers were assessed for solubility and swelling behaviour, as well as for their thermal properties, which were in line with expectations for these permanent networks. More striking results were obtained when the viscoelastic behaviour, with respect to mechanical stress-relaxation, was investigated. As hypothesized, the dynamic properties of these vitrimers, all sharing exactly the same bond exchange moieties, were found to be significantly affected by the changing backbone interspacers, quite similarly to changing solvent polarity or concentration in solution phase organic reactions.

Although these results could be partially rationalised within the context of the reaction mechanisms so far postulated to be responsible for the dynamic bond exchanges, at this point it remains challenging to come to general rules of thumb or predictions that can be made for the effect a polymer matrix can have on vitrimer properties. Nevertheless, it is clear that the viscoelastic properties of vitrimers are influenced by several parameters such as polarity, solvatation, cross-linking density and degree of flexibility.

Therefore, we end this paper with some advice and a warning for future research in vitrimer chemistry. The advice is to perform, whenever possible, assessment of vitrimer chemistries in various matrices, without expecting a priori a similar performance. Huge changes may present themselves and claims of the 'generality' of a new chemistry platform for vitrimers may be unwarranted in the absence of cross-matrix data

\section{Conflicts of interest}

There are no conflicts to declare.

\section{Acknowledgements}

YS, CT, and MG acknowledge the Research Foundation-Flanders (FWO) for the PhD and Postdoctoral fellowships. The authors would like to thank Bernhard de Meyer for the technical support. The authors would also like to thank Dr. Nezha Badi for valuable input. FDP thanks BOF-UGent (GOA-funding).

\section{References}

1. D. Montarnal, M. Capelot, F. Tournilhac and L. Leibler, Science, 2011, 334, 965-968.

2. W. Denissen, J. M. Winne and F. E. Du Prez, Chem. Sci., 2016, 7, 30-38.

3. J. M. Winne, L. Leibler and F. E. Du Prez, Polym. Chem., 2019, 10, 6091-6108.

4. V. Montano, S. J. Picken, S. van der Zwaag and S. J. Garcia, PCCP, 2019, 21, 10171-10184.

5. W. Denissen, G. Rivero, R. Nicolaÿ, L. Leibler, J. M. Winne and F. E. Du Prez, Adv. Funct. Mater., 2015, 25, 2451-2457.

6. M. Capelot, D. Montarnal, F. Tournilhac and L. Leibler, J. Am. Chem. Soc., 2012, 134, 7664-7667.

7. D. J. Fortman, J. P. Brutman, C. J. Cramer, M. A. Hillmyer and W. R. Dichtel, J. Am. Chem. Soc., 2015, 137, 1401914022.

8. M. M. Obadia, B. P. Mudraboyina, A. Serghei, D. Montarnal and E. Drockenmuller, J. Am. Chem. Soc., 2015, 137, 60786083.

9. Y. Nishimura, J. Chung, H. Muradyan and Z. Guan, J. Am. Chem. Soc., 2017, 139, 14881-14884.

10. O. R. Cromwell, J. Chung and Z. Guan, J. Am. Chem. Soc., 2015, 137, 6492-6495.

11. W. A. Ogden and Z. Guan, J. Am. Chem. Soc., 2018, 140, 6217-6220.

12. X. Chen, L. Li, K. Jin and J. M. Torkelson, Polym. Chem., 2017, 8, 6349-6355.

13. F. Caffy and R. Nicolaÿ, Polym. Chem., 2019, 10, 3107-3115.

14. A. Rahimi and J. M. García, Nat. Rev. Chem., 2017, 1, 0046.

15. C. Jehanno and H. Sardon, Nature, 2019, 568, 467-468.

16. J. S. A. Ishibashi and J. A. Kalow, ACS Macro Lett., 2018, 7, 482-486.

17. R. L. Snyder, D. J. Fortman, G. X. De Hoe, M. A. Hillmyer and W. R. Dichtel, Macromolecules, 2018, 51, 389-397.

18. M. Röttger, T. Domenech, R. van der Weegen, A. Breuillac, R. Nicolaÿ and L. Leibler, Science, 2017, 356, 62-65.

19. B. Hendriks, J. Waelkens, J. M. Winne and F. E. Du Prez, ACS Macro Lett., 2017, 6, 930-934.

20. H. Zhang, D. Wang, W. Liu, P. Li, J. Liu, C. Liu, J. Zhang, N. Zhao and J. Xu, J. Polym. Sci., Part A: Polym. Chem., 2017, 55, 2011-2018.

21. A. Ruiz de Luzuriaga, R. Martin, N. Markaide, A. Rekondo, G. Cabanero, J. Rodriguez and I. Odriozola, Mater. Horiz., 2016, 3, 241-247.

22. F. I. Altuna, C. E. Hoppe and R. J. J. Williams, Eur. Polym. J., 2019, 113, 297-304.

23. P. R. Christensen, A. M. Scheuermann, K. E. Loeffler and B. A. Helms, Nat. Chem., 2019, 11, 442-448.

24. C. He, S. Shi, D. Wang, B. A. Helms and T. P. Russell, J. Am. Chem. Soc., 2019, 141, 13753-13757.

$25 . \quad$ O. M. M., J. Antoine, C. Philippe, M. Damien and D. Eric, Adv. Funct. Mater., 2017, 27, 1703258.

26. R. Pagni, J. Chem. Educ., 2005, 82, 382.

27. C. K. Lyon, A. Prasher, A. M. Hanlon, B. T. Tuten, C. A. Tooley, P. G. Frank and E. B. Berda, Polym. Chem., 2015, 6, 181-197. 
28. M. Gonzalez-Burgos, A. Latorre-Sanchez and J. A. Pomposo, Chem. Soc. Rev., 2015, 44, 6122-6142.

29. Y. Tezuka, Polym. J., 2012, 44, 1159-1169.

30. W. Denissen, I. De Baere, W. Van Paepegem, L. Leibler, J. Winne and F. E. Du Prez, Macromolecules, 2018, 51, 20542064.

31. W. Denissen, M. Droesbeke, R. Nicolay, L. Leibler, J. M. Winne and F. E. Du Prez, Nat. Commun., 2017, 8, 14857.

32. J. J. Lessard, L. F. Garcia, C. P. Easterling, M. B. Sims, K. C. Bentz, S. Arencibia, D. A. Savin and B. S. Sumerlin, Macromolecules, 2019, 52, 2105-2111.

33. Y. Spiesschaert, M. Guerre, L. Imbernon, J. M. Winne and F. Du Prez, Polymer, 2019, 172, 239-246.

34. Z. Liu, C. Zhang, Z. Shi, J. Yin and M. Tian, Polymer, 2018, 148, 202-210.

35. C. Taplan, M. Guerre, J. M. Winne and F. E. Du Prez, Mater. Horiz., 2020, 7, 104-110.

36. T. Wright, T. Tomkovic, S. G. Hatzikiriakos and M. O. Wolf, Macromolecules, 2019, 52, 36-42.

37. M. Guerre, C. Taplan, R. Nicolaÿ, J. M. Winne and F. E. Du Prez, J. Am. Chem. Soc., 2018, 140, 13272-13284.

38. S. Ray and R. P. Cooney, in Handbook of Environmental Degradation of Materials, ed. M. Kutz, Elsevier, 2013, DOI: https://doi.org/10.1016/C2010-0-66227-4, ch. 7, pp. 213242.

39. Z. Feng, B. Yu, J. Hu, H. Zuo, J. Li, H. Sun, N. Ning, M. Tian and L. Zhang, Industrial \& Engineering Chemistry Research, 2019, 58, 1212-1221.

40. S. Dhers, G. Vantomme and L. Avérous, Green Chemistry, 2019, 21, 1596-1601.

41. S. Wang, S. Ma, Q. Li, W. Yuan, B. Wang and J. Zhu, Macromolecules, 2018, 51, 8001-8012. 